\title{
Evaluation of the Effect of the Incorporation of Rubber Tire Waste Particles on the Properties of PP, HIPS and PP/HIPS Matrices
}

\author{
Larissa Stieven Montagna, Leonardo Souza Bento, Mauro Ricardo da Silva Silveira, Ruth Marlene Campomanes Santana \\ Department of Material Engineering, Federal University of Rio Grande do Sul, UFRGS
}

\begin{abstract}
In recent years, the consumption of plastics has been increasing and as consequence, the waste generated has also increased. Rubber tire (RT) waste is another residue which causes significant problems to society. In view of the considerable amounts of RT waste generated, this study aimed to evaluate the influence of the incorporation of RT particles into post-consumer thermoplastic matrices such as polypropylene (PP), high impact polystyrene (HIPS) and PP/HIPS blends and the modification of the physical, morphological, rheological and mechanical properties. The particle sizes of the RT used were $<500$ and $500-1000 \mu \mathrm{m}$. The RT content was $10 \%$ w/w and the weight ratio for the PP/HIPS blend was $4 / 1$, with processing by injection molding. The results showed that the smaller $(500 \mu \mathrm{m})$ particle size led to a decrease in the melt flow rate (MFR) of the PP/RT composites (increased viscosity) and an increase for the HIPS/RT composites. On the other hand, the larger particles $(1000 \mu \mathrm{m})$ led to a decrease in the mechanical performance of the PP/RT and HIPS/RT blends when compared with the neat polymers (PP and HIPS post-consumer). The observed decrease in the mechanical properties of these composites was due to weak filler/matrix interactions, which can be visualized in images by scanning electron microscopy (SEM) of the fracture surface after tensile testing.
\end{abstract}

Keywords: Recycling, polypropylene, high impact polystyrene, rubber tire waste.

\section{Introduction}

A large proportion of municipal solid waste (MSW) is composed of polymeric blends, plastics and polymer composites. The processing of polymeric blends for recycling has been achieved successfully, but the low mechanical properties and uncertain economic value limit their more versatile reuse. Polyethylene (PE), polypropylene (PP), polyethylene terephthalate (PET), poly(vinyl chloride) (PVC) and polystyrene (PS) are among the most common waste plastics, and they are predominantly used in packaging for food and other products ${ }^{[1]}$. In 2010, approximately 5 million tons of plastics were produced in Brazil ${ }^{[2]}$ and therefore the rates of consumption and waste generation of plastic solid waste (PSW) has increased considerably. Thus, PSW recycling has been the focus of many researchers in the past few decades. This research is also driven by changes in regulatory and environmental issues $^{[3]}$.

Another problem of concern to society as a whole is the increasing amount of rubber tire waste. In Brazil from 1999 to $2004,39 \%$ of the 386 tons of post-consumer tire generated was used in the cement industry as a source of energy ${ }^{[4]}$. However, this use produces another problem, i.e., environmental pollution due to emissions of air pollutants and greenhouse gases.

Recycling is a good alternative for the elimination of postconsumer plastic, as it generates new materials with equal or better properties than the raw materials, using practical and, above all, inexpensive methods $s^{[5,6]}$.

The reuse of rubber tire waste (RT) dispersed in a thermoplastic matrix provides the opportunity to design materials that can be recycled in the future. This is because the thermoplastic matrix can become elastic, thus presenting better mechanical behavior ${ }^{[7]}$. Many studies have been performed to investigate the use of postconsumer rubber tires and, among other applications, their use in granulated form as an aggregate or an additive in concrete represents a possible solution to the problem of the disposal of post-consumer tires by reusing them as a resource, because when added to concrete they can improve its initial properties with satisfactory results ${ }^{[8-11]}$.
Researchers have reviewed this subject in great detail ${ }^{[9-12]}$. It has been suggested that concrete containing post-use tires could be used in asphalt for road construction, being a good shock absorber. It could also be used to deal with tremors in buildings or for structures on barriers to prevent impact. It has also been proposed that concrete containing post-use tires could be used as building material and in soil and water conservation. There are numerous applications of waste tires including their use in asphalt mixtures, in the manufacture of car mats or tatami as well as a source of rubber for the manufacture of shoes soles, crash barriers for road use and even in the construction of reefs for the breeding of marine species ${ }^{[11,12]}$.

The legislation considers that tires, including inoperable or abandoned and inadequately deposited tires, constitute an environmental liability, resulting in a serious risk to public health. Therefore, the legislation has sought solutions through environmentally and economically acceptable methods, such as the recycling of waste tires ${ }^{[7]}$. Some studies have been carried out on the use of post-use tires incorporated into a polymer matrix, but they are limited in number ${ }^{[13-15]}$.

The production of modified polymers involves several stages, since the various properties are dependent on factors such as the composition of the mixture, processing conditions, additives and temperature of application ${ }^{[10]}$.

One of the most widely used thermoplastics is PP, which is applied in packaging and in the textile and automobile industries due to its good processability. However, its application in thermoplastic engineering is somewhat limited due to its low impact resistance, especially at room temperature and at low temperatures ${ }^{[10]}$. High impact polystyrene (HIPS) is a versatile thermoplastic as a result of variations in the composition and morphology of the rubber phase dispersed in the styrenic matrix ${ }^{[16]}$. It is a material with wide application in industrial goods, for example, it is used in the production of parts for electronic devices, including radios, televisions, and computers, as well as for machines and cars. It is also used in the footwear industry, among other applications ${ }^{[17]}$. 
However, the wide application of these thermoplastics means that a large volume of post-consumption waste is generated.

In relation to the recycling of post-consumer plastic containers, such as those made of PP and HIPS, from dumps, uncultivated land and landfills (high level of contamination), the heterogeneity of the materials results not only in higher costs but also greater environmental impact. The successful recycling of disposed post-consumer packaging material disposed post-consumer is closely associated with cultural factors related to population characteristics, efficiency of selective collection, development of compatible technologies and economic and technically viable equipment for recycling routes, reduction in taxation or tax exemption for the marketing of recycled products, and legal sanctions for actions or non-integrated systems of agents in the production-use-consumer recycling chain ${ }^{[18,19]}$.

The aim of this study was to incorporate tire scraps into postconsumer PP or HIPS as the polymeric matrix and to study the influence of the particle size on the interfacial interaction between the filler (RT) and the thermoplastic matrix, with a weight proportion of thermoplastic to rubber tire waste of $90 / 10$, based on studies by Montagna \& Santana, 2008 ${ }^{[20]}$, where this ratio presented the best results $^{[21]}$.

\section{Experimental}

\section{Materials}

The materials used in this study were polypropylene (PP), high impact polystyrene (HIPS) and post-consumer rubber tire waste (RT). The PP and HIPS samples were collected from a recycling company in Santa Cruz do Sul, RS, Brazil, and the RT in the particle form was obtained from a tire retreading company situated in the city of Venâncio Aires, RS, Brazil.

\section{Processing}

The PP and HIPS waste samples were ground, washed and dried at $65{ }^{\circ} \mathrm{C}$, and then submitted to final milling with size reduction and the production of flakes in a knife mill (EBERLE - Model: B13264). The tire particle sizes were separated in a system of sieves (Bertel) of the Tyler series (60 and 24 mesh corresponding to $500 \mu \mathrm{m}$ and $1000 \mu \mathrm{m}$, respectively). The RT content used was $10 \% \mathrm{w} / \mathrm{w}$ and the weight ratio of the PP/HIPS blend was $4 / 1$, as shown in Table 1 . These composites were processed by injection molding (HIMACO, LHS130-400T) into the samples for mechanical tests to determine the tensile and flexural strength, with an injection pressure of $60 \mathrm{bar}$ and temperature of $220^{\circ} \mathrm{C}$.

\section{Characterization}

These samples were characterized by physical, morphological, rheological and mechanical properties. The density of the composites was determined by picnometry using a method based

Table 1. Composition of the materials studied.

\begin{tabular}{lcc}
\hline Sample & $\begin{array}{c}\text { Mass ratio } \\
\text { PP/HIPS/RT }(\% \mathbf{w} / \mathbf{w})\end{array}$ & $\begin{array}{c}\text { Particle Size of RT } \\
(\mu \mathbf{m})\end{array}$ \\
\hline PP & 100 & - \\
PP/RT & $90 / 0 / 10$ & 500 \\
PP/RT & $90 / 0 / 10$ & 1000 \\
HIPS & 100 & - \\
HIPS/RT & $0 / 90 / 10$ & 500 \\
HIPS/RT & $0 / 90 / 10$ & 1000 \\
PP/HIPS/RT & $72 / 18 / 10$ & 500 \\
PP/HIPS/RT & $72 / 18 / 10$ & 1000 \\
\hline
\end{tabular}

on the ISO 1183-1:2004(E) standard and the void content of the composites was determined based on ASTM D2734-94. The rheological tests were carried out by capillary rheometer using a Galaxy III rheometer (Kayeness Inc.) and the melt flow rate using a plastometer (CEAST Melt Flow Junior), according to ASTM D1238-95 and ASTM D3835, respectively. The melt flow rate of the materials was measured at $230^{\circ} \mathrm{C}$ with a load of $2.16 \mathrm{~kg}$ for mixtures containing PP and at $190{ }^{\circ} \mathrm{C}$ with a load of $5 \mathrm{~kg}$ for mixtures with HIPS. Seven tests were performed for each material to provide better accuracy ${ }^{[22,23]}$. The morphology analysis of the fracture surface of the PP/RT, HIPS/RT and (PP/HIPS)/RT composites after the tensile tests was carried out using a scanning electron microscope (SEM), model Philips XL 20. Samples were covered with gold before being examined under the microscope at an acceleration voltage of $20 \mathrm{kV}$.

The tensile and flexural strengths of the mixtures were determined in a universal testing machine (EMIC), according to ASTM D638-93, with a test speed of $50 \mathrm{~mm} / \mathrm{min}$ and strength of $4 \mathrm{kN}$ for tensile strength and test speed of $5.1 \mathrm{~mm} / \mathrm{min}$ and span of $96 \mathrm{~mm}$ for flexural strength. The impact strength of the samples was determined in a CEAST-IMPACT II analyzer, based on ASTM D256-04, with pendulums of $2.75 \mathrm{~J}$ and $11 \mathrm{~J}$.

\section{Results and Discussion}

\section{Physical properties}

\section{Density and void content}

Figure 1a shows the density of the post-consumer polymers and their composites. The RT particles have a density higher than those of the PP and HIPS matrices; however the incorporation of tires scraps into the polymers matrix causes a reduction in density when compared with the neat polymer. The tires scraps have a greater density than the PP and HIPS mixtures, due to the voids and poor homogenization, as observed in Figure 1b. Also, it was observed that an increase in the RT particle size led to a reduction in the density due to an increase in the void content of the polymer blends, a result that was consistent with the morphological properties of the fracture surface showed in Figures 2 and 3 and verified by reports in the literature ${ }^{[24]}$.

\section{Morphological properties}

Figures 2 and 3 show the micrographs of the fracture surface after the tensile tests for the PP/RT and HIPS/RT composites $(90 / 10 \% \mathrm{wt})$, respectively, with a magnification of $60 \times$. In Figure $2 \mathrm{a}$ the presence of small cavities can be observed on the fracture surface of the PP/RT composite due to the removal of RT particles $(<500 \mu \mathrm{m})$ during the tensile test, indicating poor interfacial interaction between the RT filler and PP matrix. On the other hand, in Figure $2 b$ the fracture surface shows a larger cavity size associated with the RT particle size of 500-1000 $\mu \mathrm{m}$. It can also be noted in both figures that the fracture of these samples was ductile, which is characteristic of $\mathrm{PP}^{[25]}$.

Figure $3 \mathrm{a}$ shows the presence of some tire rubber particles of the smaller size $(<500 \mu \mathrm{m})$ in the HIPS matrix. This result indicates that the RT has a larger surface area and therefore greater dispersion in the polymer matrix resulting in smaller cavities. The presence of some RT particles of the larger size $(500-1000 \mu \mathrm{m})$ remaining in the thermoplastic matrix (HIPS) can be observed in Figure 3b. These results may reflect a better interfacial interaction between these phases, possibly due to the presence of polybutadiene in the HIPS.

On comparing Figures 2 and 3 a difference in the morphology of the fracture surfaces can be observed. The ductile fracture characteristic of polypropylene (PP) is observed in Figure 2, and 
in Figure 3 the fragile fracture corresponds to the rigid matrix characteristic of the high impact polystyrene (HIPS), confirming the mechanical test results.

In the case of the blend matrix (PP/HIPS) filled with RT, in Figure 4 an increase in the roughness can be observed due to the heterogeneity of the surface morphology. Figure $4 \mathrm{a}$ in particular shows regions of ductile fracture corresponding to the PP ( $72 \% \mathrm{wt})$ and some areas of fragile fracture corresponding to the HIPS $(18 \% \mathrm{wt})$. Therefore the presence of PP led to an increase in the ductile behavior of the material.

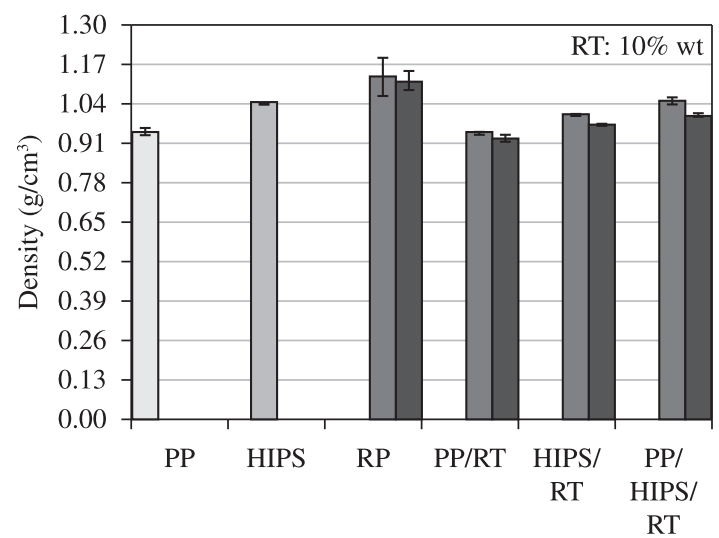

$\square \mathrm{PP} \quad \square$ HIPS $\square 500 \quad \square 1000$
It is also possible to observe in the micrograph of Figure $4 \mathrm{a}$ a greater number of smaller cavities on the fracture surface of the composite, related to RT of particle size $<500 \mu \mathrm{m}$. In contrast, Figure $4 \mathrm{~b}$ shows larger cavities. These cavities were formed by the removal of RT particles during the tensile test. As in Figure 3, it is possible to observe the presence of some RT particles in the thermoplastic matrix (PP/HIPS).

On analyzing all of the micrographs, the presence of particles can be observed only when the matrix contains HIPS, indicating that this leads to a better interaction of the RT with the matrix

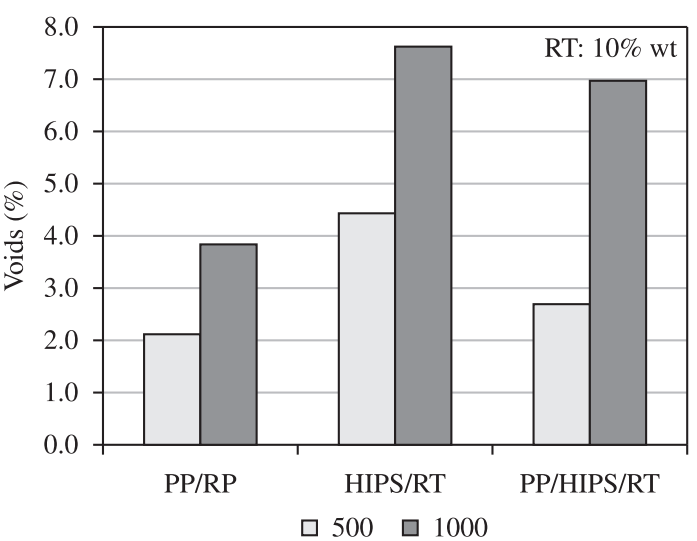

Figure 1. Physical properties of PP, HIPS, RT and composites: (a) density and (b) void content.

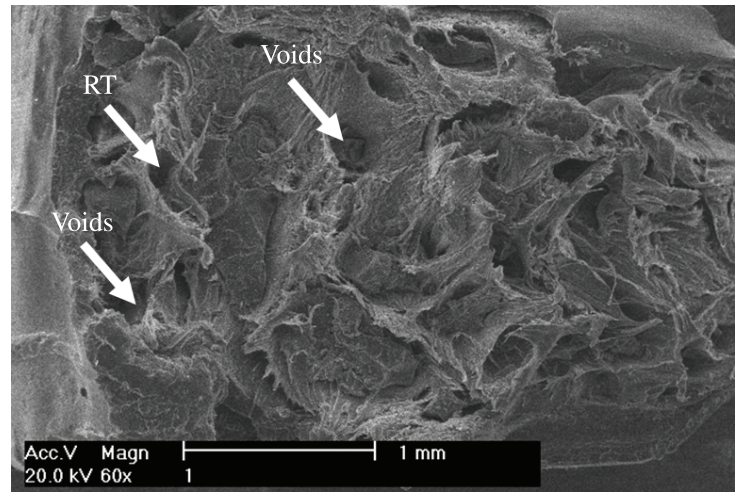

(a)

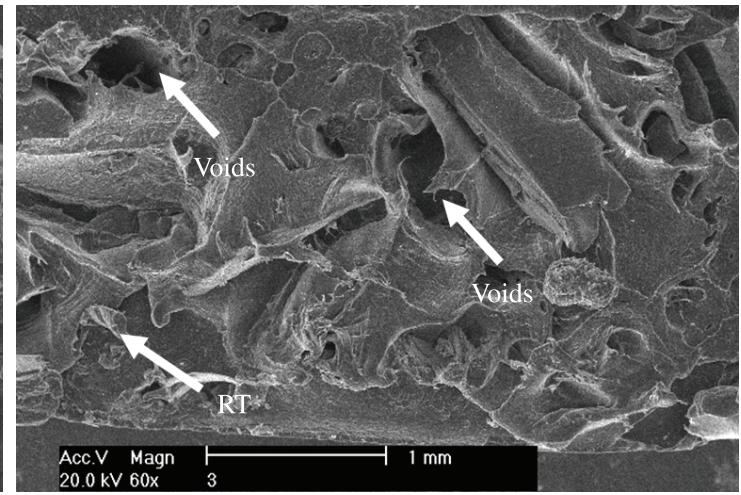

(b)

Figure 2. SEM micrographs of fracture surface after tensile test of PP/RT (90/10) composites with RT particle size of (a) $<500 \mu \mathrm{m}$ and (b) $500-1000 \mu \mathrm{m}$ (magnification 60x).

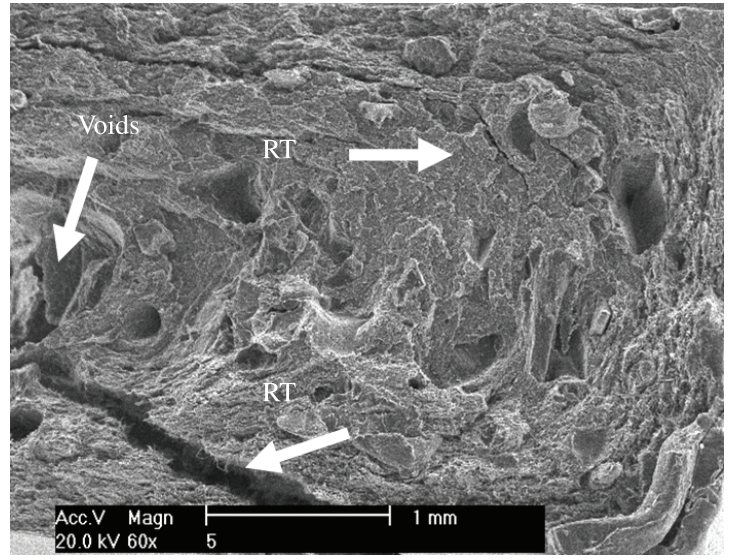

(a)

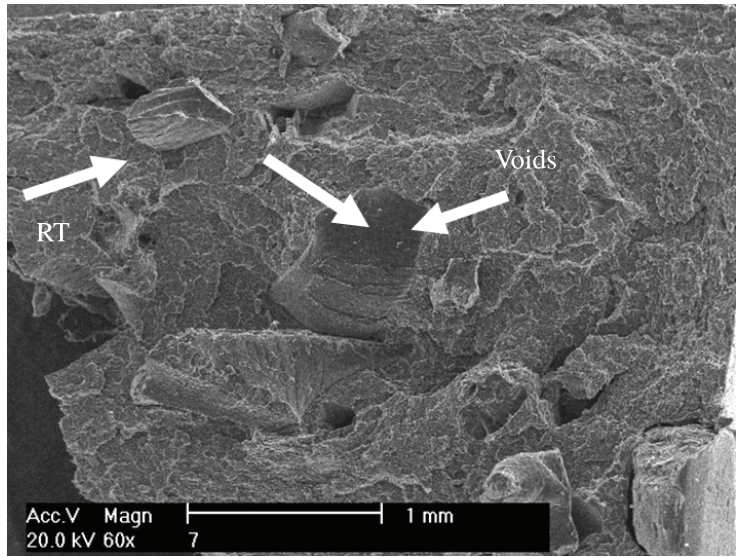

(b)

Figure 3. SEM micrographs of fracture surface after tensile test of HIPS/RT (90/10) composites with particle size of RT of (a) $<500 \mu \mathrm{m}$ and (b) $500-1000 \mu \mathrm{m}$ (magnification 60x). 
(HIPS). In Figure 2, where the matrix contains only PP, the absence of RT particles on the fracture surface of the PP/RT composites is evidenced by the presence of cavities $(<500 \mu \mathrm{m}$ and $500-1000 \mu \mathrm{m})$ formed during the tensile test. Similar results have been obtained by other authors ${ }^{[26-28]}$.

\section{Rheological properties}

Figure 5 shows the curves for the apparent viscosity and the MFR of PP, HIPS and their composites with rubber tire (RT) scraps, obtained by capillary rheometry and plastometry, respectively.
Samples of PP and PP/RT (90/10 \%wt) showed the same decay profile as the apparent viscosity as a function of the shear rate measured, as shown in Figure 5a, although it was observed that the curve for the PP/RT sample, with particle size of 500-1000 $\mu \mathrm{m}$, was slightly lower than the others. This trend can be seen more clearly in Figure 5d, where the value for MFR is higher for PP than for the PP/filled with RT particles of $<500 \mu \mathrm{m}$.

On the other hand, samples of HIPS and HIPS/RT (90/10 \%wt) with RT particle size of 500-1000 $\mu \mathrm{m}$ showed similar profiles for the viscosity as a function shear rate, as shown in Figure $5 \mathrm{~b}$. The

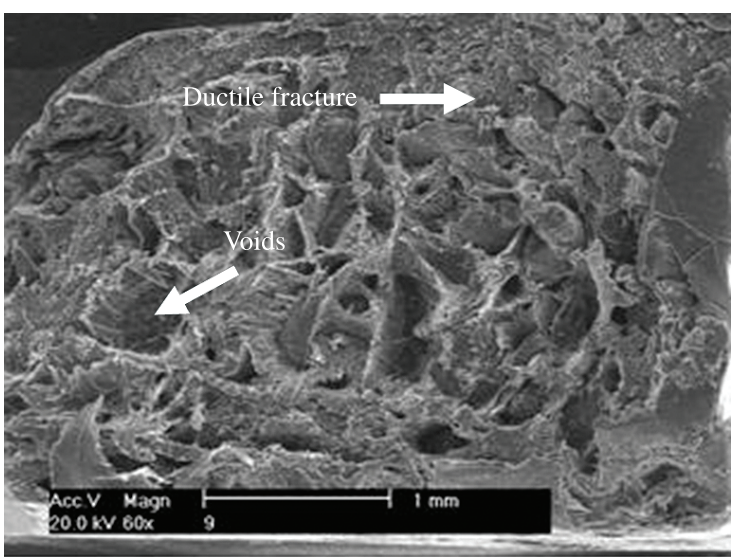

(a)

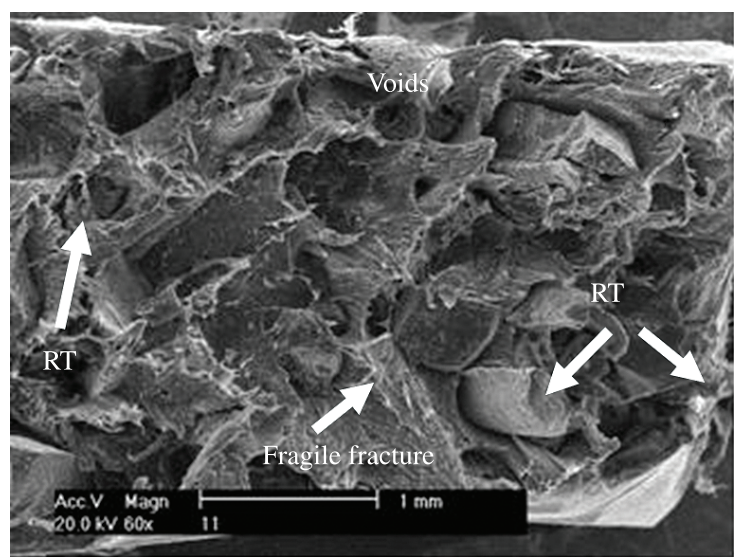

(b)

Figure 4. SEM micrographs of fracture surface after tensile test of the PP/HIPS/RT (72/18/10) composites with RT particle sizes of (a) <500 $\mu \mathrm{m}$ and (b) $500-1000 \mu \mathrm{m}$ (magnification $60 \times$ ).

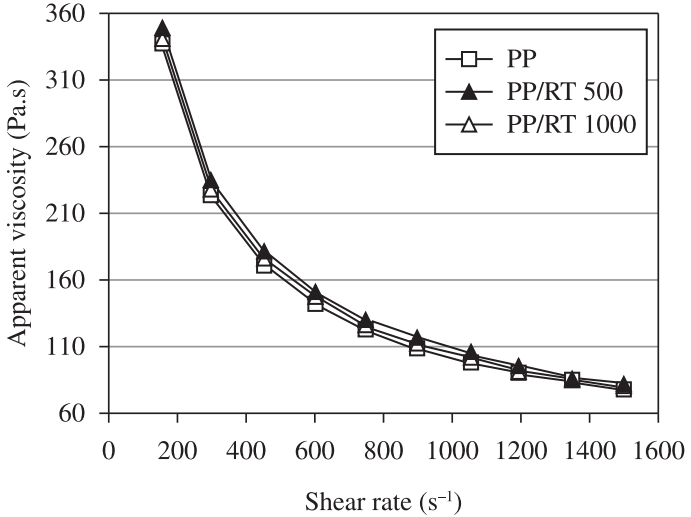

(a)

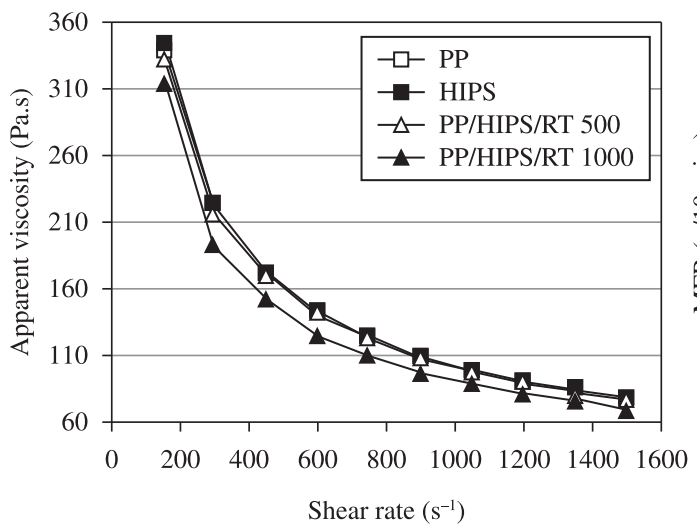

(c)

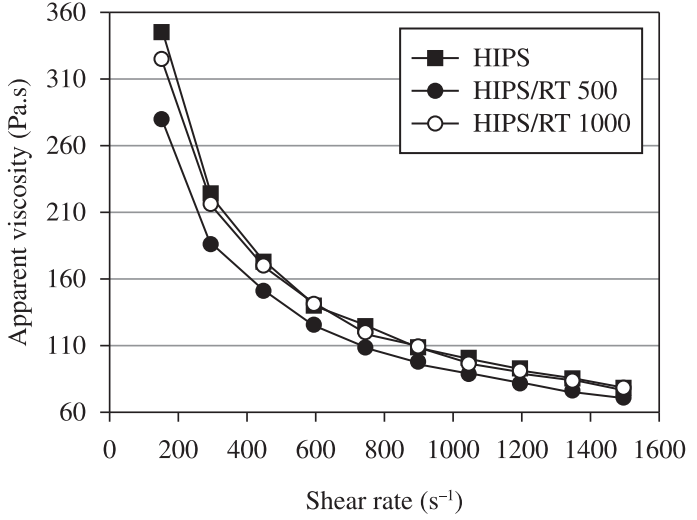

(b)

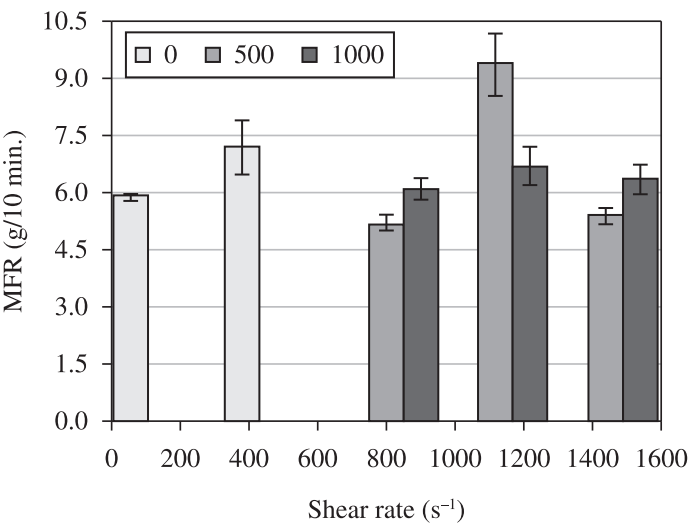

(d)

Figure 5. Rheological Properties: (a) Viscosity profiles for PP and its composites filled with RT ( $<500$ and 500-1000 $\mu \mathrm{m}$ ), (b) Viscosity profile for HIPS and its composites with RT $(<500$ and 500-1000 $\mu \mathrm{m})$, (c) Viscosity profile for PP/HIPS/RY ( $<500$ and 500-1000 $\mu \mathrm{m})$, (d) MFR for the PP, HIPS and PP/HIPS/RT mixtures $(<500$ and $500-1000 \mu \mathrm{m})$. 
HIPS matrix filled with RT (10\%), Figure 5c showed a significant decrease in viscosity. These results are confirmed by the high MFR of the mixture of HIPS/RT with RT particle size of $<500 \mu \mathrm{m}$, as can be seen in Figure 5d.

In the case of the PP/HIPS (72/18 \%wt) matrix filled with RT (10\% wt) the profile for the viscosity was similar to that of PP/RT. This is because in the polymer matrix (PP/HIPS) the largest proportion by weight was that of the PP $(72 \%)$. However, the increase in the particle size to 500-1000 $\mu \mathrm{m}$ led to a decrease in the viscosity and an increase in MFR because HIPS has a higher $\operatorname{MFR}^{[15,20]}$.

\section{Mechanical properties}

\section{Tensile strength}

Figure 6 shows the results of the Young's modulus for the samples of PP, HIPS and their composites filled with $10 \%$ wt of RT obtained in the tensile test. It was observed that the HIPS/RT mixture has a higher modulus than the PP/RT blend, indicating that the former mixture is rigid and influenced by the characteristics of HIPS. Regarding the particle size of the RT, there was a decrease in the Young's modulus with an increase in the particle size of RT from $<500$ to $500-1000 \mu \mathrm{m}$, which could be due to the smaller number of particles incorporated in the matrix when compared to the smaller size which acts as a filler and increases the rigidity ${ }^{[14]}$.

\section{Flexural strength}

Figure 7 shows the modulus results for PP, HIPS and the composites filled with RT (10\% wt) obtained in the flexural test. It can be observed that mixtures containing HIPS present a higher flexural modulus than those of PP/RT, which may be explained by the presence of poly(butadiene) in HIPS. An increase in the particle size of the RT present in the HIPS/RT mixtures provided an overall insignificant decrease in the modulus of the composites and in the case of the PP/RT mixture there was a slight increase.

\section{Impact strength}

Figure 8 shows the impact strength results for PP, HIPS, and the composites filled with RT (10\% wt). In the case of PP a higher amount of the impact energy is absorbed compared with HIPS, as expected since the HIPS is a rigid material with a glass transition temperature ${ }^{[23]}$ above room temperature (it should be noted that for the PP it was necessary to use a pendulum of $11 \mathrm{~J}$, greater than that of $2.75 \mathrm{~J}$ used for the HIPS and the composites).

The incorporation of RT led to a decrease in the amount of impact energy absorbed, and the reduction was most significant for the HIPS/RT composite, confirming the low deformation observed in the tensile and flexural essays, indicating that these mixtures are more rigid due to the presence of HIPS. Although this contains polybutadiene, the content is generally less than that of RT $(10 \% \mathrm{wt})$, so the greater rigidity corresponds to the polystyrene ${ }^{[23,28]}$.

Regarding the influence of the particle size of the RT in the mixture, in general, there was a decrease in the amount of impact energy absorbed with increasing RT particle size from $<500$ to $500-1000 \mu \mathrm{m}$. This result may be due to the smaller RT particles $(<500 \mu \mathrm{m})$ having better interaction with the polymer matrix, caused by several factors, mainly the larger contact area and the chemical composition of HIPS which, as previously mentioned, contains polybutadiene in its composition ${ }^{[21,28]}$.

Table 2 reports the mechanical properties and it can be observed that the PP and its composites filled with $10 \%$ wt RT showed better mechanical performance, while the results for the tensile strength, deformation and energy absorption were higher than the corresponding values for HIPS and its composites. Compared with the results for the flexural test, it was observed that HIPS and its composites showed better mechanical performance than PP and its composites.

The influence of the RT particle size in the mixtures was also observed, where the particles of $<500 \mu \mathrm{m}$ showed reduced loss in the mechanical properties evaluated in comparison with mixtures containing RT particles of 500-1000 $\mu \mathrm{m}$.

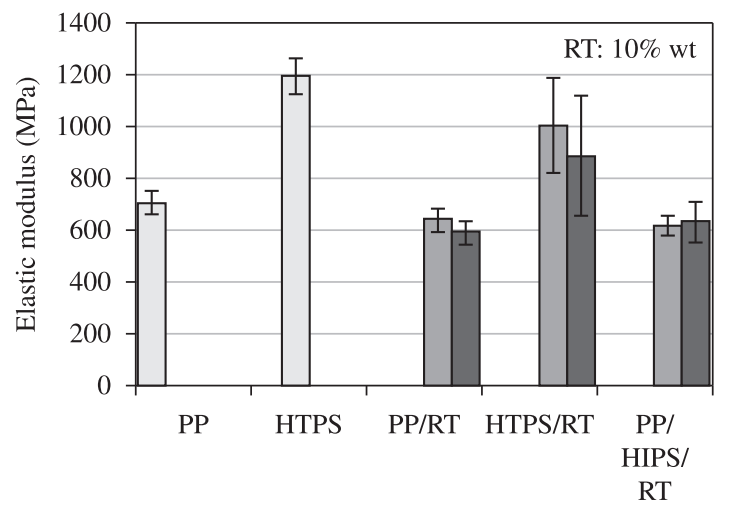

Sample

$\square \mathrm{RT}(0) \quad \square \mathrm{RT}(0) \quad \square \mathrm{RT}(500) \quad \square \mathrm{RT}(1000)$

Figure 6. Elastic modulus for PP, HIPS and PP/HIPS/RT mixture with RT particles of $<500$ and $500-1000 \mu \mathrm{m}(10 \% \mathrm{wt})$.

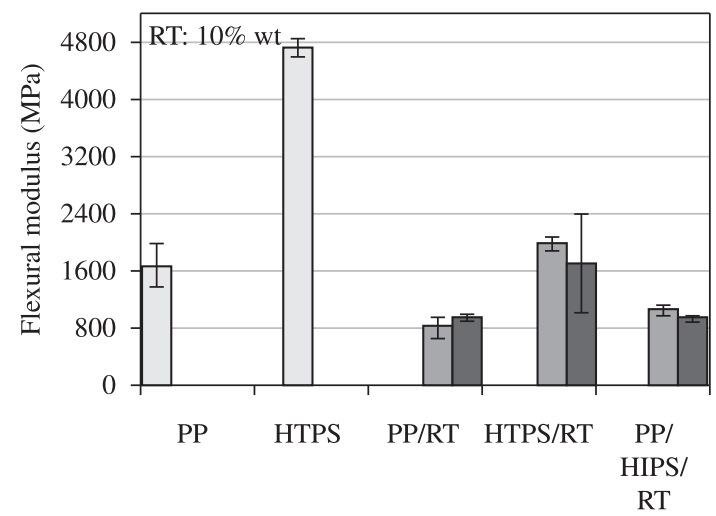

Sample

$\square \mathrm{RT}(0) \quad \square \mathrm{RT}(0) \quad \square \mathrm{RT}(500) \quad \square \mathrm{RT}(1000)$

Figure 7. Flexural modulus for PP, HIPS and PP/HIPS/RT mixture with RT particles of $<500$ and $500-1000 \mu \mathrm{m}(10 \% \mathrm{wt})$.

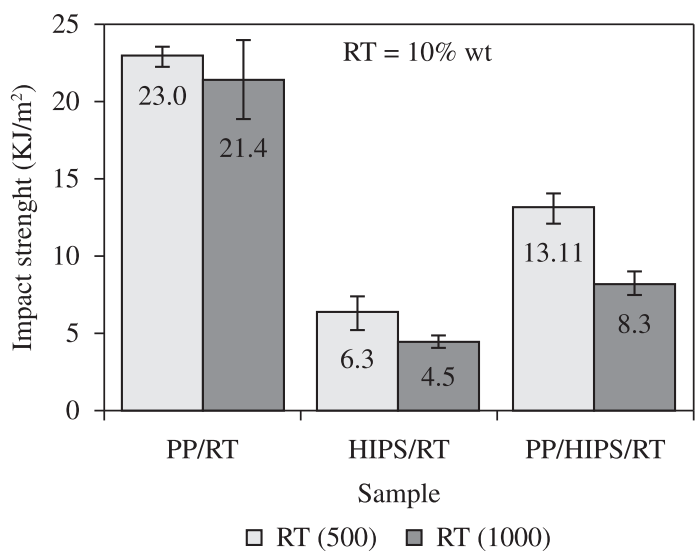

Figure 8. Impact strength of PP, HIPS and PP/HIPS/RT mixture with RT particles of $<500$ and $500-1000 \mu \mathrm{m}(10 \% \mathrm{wt})$. 
Table 2. Results of tensile and flexural tests for PP, HIPS and their composites PP/RT, HIPS/RT and PP/HIPS/RT.

\begin{tabular}{lcccccc}
\hline \multirow{2}{*}{ Samples } & \multirow{2}{*}{$\begin{array}{c}\text { Particle size of RT } \\
(\mu \mathbf{m})\end{array}$} & $\mathbf{R}(\mathbf{M P a})$ & $\varepsilon(\boldsymbol{\%})$ & \multicolumn{2}{c}{ Tensile } & \multicolumn{2}{c}{$\begin{array}{c}\text { Impact Strength } \\
\left(\mathbf{k J} / \mathbf{m} \mathbf{m}^{2}\right)\end{array}$} \\
\cline { 1 - 6 } PP & - & $16.7 \pm 1.6$ & $669.2 \pm 71.9$ & $44.2 \pm 1.2$ & $4.1 \pm 0.4$ & $48.4 \pm 16.3$ \\
HIPS & - & $12.5 \pm 1.5$ & $15.3 \pm 2.4$ & $80.2 \pm 0.9$ & $2.8 \pm 0.1$ & $18.6 \pm 1.5$ \\
& 500 & $11.4 \pm 0.8$ & $17.9 \pm 1.8$ & $18.9 \pm 1.6$ & $4.0 \pm 0.1$ & $23.0 \pm 0.6$ \\
PP/RT & 1000 & $8.8 \pm 0.5$ & $10.0 \pm 1.1$ & $20.3 \pm 0.6$ & $4.0 \pm 0.2$ & $21.4 \pm 2.5$ \\
& 500 & $6.9 \pm 1.3$ & $1.5 \pm 0.3$ & $32.6 \pm 1.6$ & $2.4 \pm 0.1$ & $6.3 \pm 1.1$ \\
HIPS/RT & 1000 & $6.4 \pm 2.9$ & $1.4 \pm 0.5$ & $31.1 \pm 7.8$ & $3.0 \pm 0.3$ & $4.5 \pm 0.4$ \\
& 500 & $6.9 \pm 0.8$ & $8.2 \pm 0.7$ & $23.1 \pm 1.7$ & $3.9 \pm 0.2$ & $13.1 \pm 1.0$ \\
(PP/HIPS)/RT & 1000 & $5.2 \pm 0.9$ & $3.4 \pm 0.7$ & $20.7 \pm 0.4$ & $3.9 \pm 0.1$ & $8.2 \pm 0.7$ \\
\hline
\end{tabular}

\section{Conclusions}

In this study the samples were classified according to their physical, rheological, morphological and mechanical properties. The results for the rheological properties indicated that the presence of smaller RT particles led to a lower MFR for the PP/RT composites (increased viscosity) and higher MFR for the HIPS/RT composites, results confirmed by capillary rheometry.

The presence of RT with larger particles in the mixtures of PP/RT and HIPS/RT led to a decrease in the mechanical performance, i.e., the tensile, flexural and impact strength. In the flexural tests, the results for the (PP/HIPS)/RT mixtures indicated that the presence of HIPS led to an increase in the flexural strength. It was observed that there was a better interaction of RT in the HIPS polymer matrix and even in the PP/HIPS matrix. In the micrographs of the fracture surface of the blends (PP, HIPS) with a concentration of $10 \% \mathrm{w} / \mathrm{w}$ RT the presence of small cavities was observed formed by the pull out of the RT during the tensile test, indicating poor interfacial interaction between RT and the PP matrix. In the HIPS matrix, a better interfacial interaction between these phases was observed, possibly due to the presence of polybutadiene in HIPS.

\section{Acknowledgments}

The authors would like to acknowledge LAPOL/UFRGS and the Analytical Center/UNISC for the mechanical tests.

\section{References}

1. Zanin, M. \& Mancini, S. D. - "Resíduos Plásticos e Reciclagem: Aspectos gerais e tecnologia". Ed.; EduFSCa, São Carlos - SP (2004).

2. Compromisso Empresarial para Reciclagem - CEMPRE. Disponível em: <http://www.cempre.org.br/fichas_tecnicas.php?lnk=ft_pneus. php>. Acesso em: 19 fev. 2012.

3. Navarro, F. J.; Partal, P.; Martínez-Boza, F. J. \& Gallegos, C. - Polym. Test., 29, p.588 (2010). http://dx.doi.org/10.1016/j. polymertesting.2010.03.010

4. Plastivida - Instituto Sócio-Ambiental dos Plásticos - Accessed on 26/04/2011 Site: http://www.plastivida.org.br/reciclagem/pes mercado02.htm

5. Conselho Nacional do Meio Ambiente - CONAMA. - "Resolução $n^{\circ}$ 258, de 26 de agosto de 1999", Ministério do Meio Ambiente, Governo Federal, Brasil (1999). Disponível em: <http://www.mma.gov. br/port/conama/res/res99/res25899.html>. Acesso em: 18 fev. 2012.

6. Scuracchio, C. H.; Waki, D. A. \& Bretas, R. E. M. - Polímeros, 16, p.46 (2006). http://dx.doi.org/10.1590/S0104-14282006000100011

7. Pinheiro, J. H. M. - "Incorporação de borracha de pneu em misturas asfálticas de diferentes granulometrias", Dissertação de Mestrado, Universidade Federal do Ceará, Brasil (2004).

8. Canevarolo, J. - "Ciência dos Polímeros: Um texto básico para tecnólogos e engenheiros", Artliber Editora, São Paulo (2002).

9. Siddique, R. \& Naik, T. R. - Waste Manag., 24, p.563 (2004). PMid:15219914. http://dx.doi.org/10.1016/j.wasman.2004.01.006
10. Pacheco-Torgal, F.; Ding, Y. \& Jalali, S. - Constr. Build. Mater., 30, p.714 (2012). http://dx.doi.org/10.1016/j.conbuildmat.2011.11.047

11. Costa, H. M.; Ramos, V. D. \& Rocha, M. C. G. - Polym. Test., 25, p.498 (2006).

12. Bertollo, S. M.; Fernandez, F. L. \& Chalch, V. - "Benefícios Da Incorporação De Borracha De Pneus Em Pavimentos Asfálticos", in: Anais do XXVIII Congreso Interamericano de Ingenieria Sanitária y Ambiental, Cancun México (2002).

13. Zhang, S.L.; Xin,Z.X.;Zhang,Z.X.\& Kim,J.K. - Waste Manag., 29, p.1480 (2009). PMid:19070475. http://dx.doi.org/10.1016/j.wasman.2008.10.004

14. Sridhar, V.; Xiu, Z. Z.; Xu, D.; Lee, S. H.; Kim, J. K.; Kang, D. J. \& Bang, D. S. - Waste Manag., 29, p.1058 (2009). PMid:18838261. http://dx.doi.org/10.1016/j.wasman.2008.08.013

15. Satapathy, J. S.; Nag, A. \& Nando, G. B. - Process Saf. Environ. Prot., 85, p.318 (2007)

16. Vianna, W. L.; Correa, C. A. \& Razzino, C. A. - Polímeros, 14, p.339 (2004).

17. Rovere, J.; Correa, C. A.; Grassi, V. G. \& Dal Pizzol, M. F. - Polímeros, 18, p.12 (2008). http://dx.doi.org/10.1590/S0104-14282008000100007

18. Forlin, F. J. - Polímeros, 12, p.1 (2002).

19. Vogt, F.; Delfino, G. P.; Roratto, A. V. G.; Herter, F. F. \& Santana, R. M. C. - "Resíduo plástico universitário: um estudo de casa para o campus da UFRGS", in: Anais do 17th Congresso Brasileiro de Engenharia e Ciência dos Materiais, Foz do Iguaçu, Brazil (2006).

20. Montagna, L. S. \& Santana, R. M. C. - "Effect of the mixing condition on structure of thermoplastic polymer/tire post-user blends", in: Anais do 24th Proceedings of the Polymer Processing Society, Salerno, Italy (2008).

21. Mohammadian-Gezaz, S.; Ghasemi, I.; Karrabi, M. \& Azizi, H. - Polym. Test., 25, p.504 (2006). http://dx.doi.org/10.1016/j. polymertesting.2006.02.002

22. Ismail, H. \& Suradiansyah, H. - Polym. Test., 21, p.389 (2002). http:// dx.doi.org/10.1016/S0142-9418(01)00101-5

23. Santana, R. M. C. \& Manrich, S. - Prog. Rubber Plast. Recycl. Technol., 18, p.99 (2002).

24. Montagna, L. M. \& Santana, R. M. C. - Plast. Rub. Compos., 41, p.256 (2012).

25. Alcock, B.; Cabrera, N. O.; Barkoula, N. \& Peijs, T. - Compos Sci. Technol., 66, p.1724 (2006). http://dx.doi.org/10.1016/j. compscitech.2005.11.010

26. Ausias, G.; Thuillier, S.; Omnès, B.; Wiessner, S. \& Pilvin, P. - Polymer, 48, p.3367 (2007). http://dx.doi.org/10.1016/j. polymer.2007.03.049

27. Awang, M.; Ismail, H. \& Hazizan, M. A. - Polym. Test., 26, p.779 (2007). http://dx.doi.org/10.1016/j.polymertesting.2007.04.007

28. Shanmugharaja, A. M.; Kimb, J. K. \& Ryu, S. H. - Polym. Test., 24, p.739 (2005).

Received: 02/03/12

Revised: 06/08/12

Accepted: 20/08/12 